\title{
Design of Low Noise Amplifier for 1.5 GHz
}

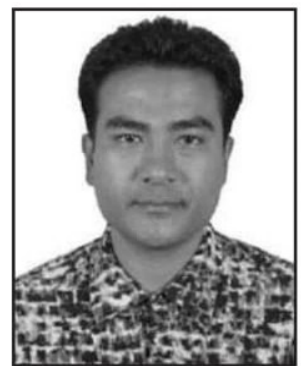

\section{Bijaya Shrestha}

Department of Electronics \& Communication Engineering, Nepal Engineering College, Pokhara University Changunarayan, Bhaktapur, Nepal shrestha.bijaya2018@gmail.com

Mr. Bijaya Shrestha has received his Master's degree in Radio Frequency Electronics from Tampere University of Technology, Finland in 2011 A.D. and Bachelor's degree in Electronics \& Communication Engineering from Pulchowk Campus, Tribhuvan University, Nepal in 2006 A.D. He is currently working at Nepal Engineering College as an Assistant Professor in the department of Electronics \& Communication Engineering since 2012 A.D.

He is interested to perform research in $R F$ electronics and communications.

\begin{abstract}
Low Noise Amplifier (LNA) is a front-end device of a radio frequency $(R F)$ receiver used to increase the amplitude of an $R F$ signal without much additional noise, thereby increasing the noise figure of the system. This paper presents design, simulation, and prototype of an LNA operating at $1.5 \mathrm{GHz}$ for the bandwidth of $100 \mathrm{MHz}$. The circuit was simulated using Advanced Design System (ADS). The components used are Surface Mount Devices (SMDs); with transistor "Infineon BFP420" as a major component. Other components are resistors, capacitors, and inductors; inductors being superseded by microstrip lines. The circuit was fabricated on FR4 board. The measurements of several parameters of LNA were made using Vector Network Analyzer (VNA), Noise Figure Meter, and Spectrum Analyzer. The LNA has minimum gain of $15.4 \mathrm{~dB}$ and maximum noise figure of $1.33 \mathrm{~dB}$. It is unconditionally stable from $50 \mathrm{MHz}$ to $10 \mathrm{GHz}$. DC supply is $5 \mathrm{~V}$ and the current consumption is $10 \mathrm{~mA}$. This LNA offers Output-ThirdOrder-Intercept-Point (OIP3) of about $14 \mathrm{dBm}$.
\end{abstract}

Keywords : Low noise amplifier, Advanced design system

\section{Introduction}

LNA is an essential device in wireless communication systems such as satellite and mobile communication systems. It is used in receiver as a front-end device as shown in Fig. 1. Providing high gain to the RF signal and adding low noise decreases the overall noise figure of the receiver as suggested by Friis formula,

$$
F=F_{1}+\frac{F_{2}-1}{G_{1}}+\frac{F_{3}-1}{G_{1} G_{2}}+\cdots+\frac{F_{n}-1}{G_{1} G_{2} \cdots G_{n-1}}
$$

where $F_{l}, F_{2}, F_{3}$, and $F_{n}$ are the noise factors of the first, second, third, and the $\mathrm{n}^{\text {th }}$ block of the cascaded system. And, $G_{I}, G_{2}, G_{3}$, and the $G_{n}$ are the corresponding gains. Noise factor in $\mathrm{dB}$ scale is called the noise figure. Decreased overall noise figure is the reason why the use of LNA and its placement in the beginning is preferred in wireless systems.

The position of LNA in a heterodyne receiver is illustrated in the Fig. 1. The receiver mainly consists of antenna, band-pass filter (BPF), LNA, mixer, oscillator, and voltage gain amplifier (VGA).

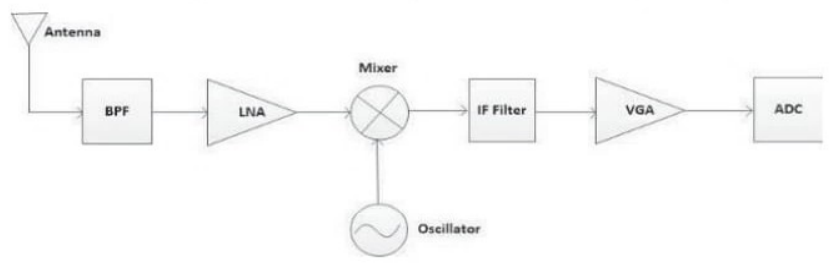

Fig. 1 Block diagram of heterodyne receiver. [1] 
This paper includes the design, simulation, and prototype of an LNA operating at $1.5 \mathrm{GHz}$ with bandwidth $100 \mathrm{MHz}$. The amplifier consists of transistor, resistors, capacitors, and inductors. All the components are SMDs: "Infineon BFP420" Bipolar Junction Transistor (BJT), 0603 capacitors and resistors. Appropriately calculated microstrip lines were used to mimic the inductors.

\section{Literature Review}

Different papers were reviewed to embark this project work. Most of the LNA designs were found to be based on CMOS technology with cascode structure. The paper [2] presents CMOS LNA design at $5.7 \mathrm{GHz}$ with gain $11.45 \mathrm{~dB}$ and noise figure $3.4 \mathrm{~dB}$. Another work at $5 \mathrm{GHz}$ has gain $9.2 \mathrm{~dB}$ and noise figure 2.8 $\mathrm{dB}$ [3]. The design at $2.4 \mathrm{GHz}$ has comparable gain of $11.2 \mathrm{~dB}$ and noise figure of $2.3 \mathrm{~dB}$ [4]. The paper [5] compares the performance of CMOS LNA and BJT LNA at $1 \mathrm{GHz}$. In this paper, the gain and noise figure of CMOS LNA was obtained as $21.64 \mathrm{~dB}$ and $1.78 \mathrm{~dB}$ respectively with the expense of huge power $23 \mathrm{~mW}$; whereas the gain and noise figure of BJT LNA was achieved to be $14.3 \mathrm{~dB}$ and $1.87 \mathrm{~dB}$ respectively with the expense of only $4.6 \mathrm{~mW}$. After analysing the performances of all the above LNA designs, I got motivated to design a simple BJT LNA with better performance at different frequency.

\section{LNA Specifications}

In practice, the specifications are made first before designing a device depending on its use. The important parameters for LNA are stability, gain, noise figure, input return loss, output return loss, and linearity.

\section{A. Stability}

LNA must be unconditionally stable for all passive source and load impedances. Stability can be described by $\mu$-factor which is calculated using S-parameters as given helow

$$
\mu=\frac{1-\left|S_{11}\right|^{2}}{\left|S_{22}-\Delta S_{11}^{*}\right|+\left|S_{12} S_{21}\right|}
$$

where

$$
\Delta=S_{11} S_{22}-S_{12} S_{21}
$$

For amplifier to be unconditionally stable, $\mu$ must be greater than 1 . The frequency range for stability was chosen from $50 \mathrm{MHz}$ to $10 \mathrm{GHz}$. [6]

\section{B. Gain, Noise Figure, Input Return Loss, and Output Return Loss}

Maximum available gain and minimum possible noise figure of BFP420 at $1.5 \mathrm{GHz}$ are $20 \mathrm{~dB}$ and $1.1 \mathrm{~dB}$ respectively if the supplied collector current is $10 \mathrm{~mA}$ [7]. If input and output ports of LNA are simultaneously conjugate matched then maximum gain is possible. Input should be matched to $Z_{O P T}$ to achieve minimum noise figure [6]. And the resistive components used for stability introduce some additional noise. So, maximum gain and minimum noise figure cannot be achieved simultaneously. The safer margin was kept and minimum gain was specified to be $15 \mathrm{~dB}$ and maximum noise figure to be $1.5 \mathrm{~dB}$.

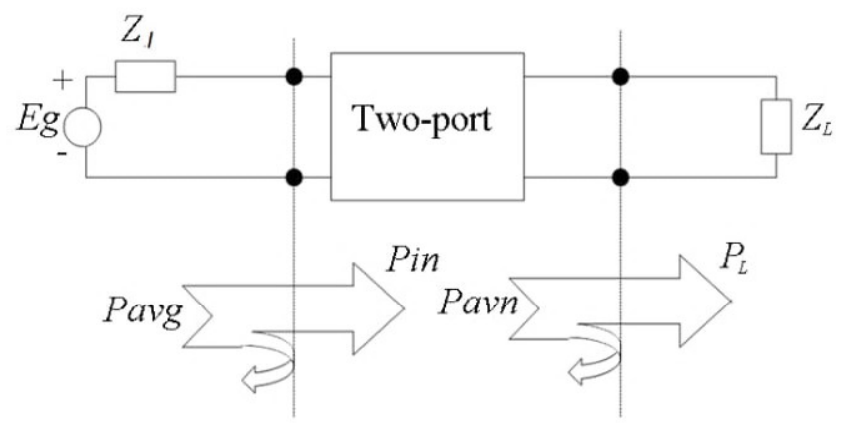

Fig. 2 Power notations in a two-port network.

In Fig. 2, $P_{a v g}$ is available power from source, $P_{i n}$ is input power to network, $P_{a v n}$ is available power from network, and $P_{L}$ is power delivered to the load. When a signal goes to the input of a two-port network, some of its power gets reflected back due to the mismatch between source impedance and input impedance. Similar is the case in the output port. The reflection of wave at interface can be described in terms of return loss. The value of return loss becomes high if the impedance matching is good. Since input was targeted for noise matching and output was for maximum gain, the input and output return losses were specified to be optimal, that is; minimum of $7 \mathrm{~dB}$ and $10 \mathrm{~dB}$ respectively.

\section{Linearity}

For an amplifier to be linear, the plot of output power versus input power must be a straight line with a slope of unity. The linearity persists over a limited range, and then the amplifier response begins to saturate providing less gain. The nonlinearity property produces harmonics and intermodulation products. The harmonic components can be filtered out; where as some of the intermodulation products of closely spaced frequencies 
may occur within the bandwidth of the amplifier. They ultimately cause distortion to the signal.

The plot of output power for the first-order and third-order products versus input power in $\mathrm{dB}$ is shown in Fig. 3. The output power of the first-order product is linearly proportional to the input power with the slope of unity. On the other hand, the response of the third-order products has a slope of 3. For high input power, both of these lines show compression. When the idealized responses are extended with the dotted lines, they intersect at a point which is known as thirdintercept point, denoted as IP3. At this point, first-order and third-order power are equal. The intercept point is specified as either an input power level (IIP3) or an output power level (OIP3).

The third-order intercept point is a theoretical point that is never achieved in practice. The usefulness of this point lies while determining the linearity condition of an amplifier. The higher the output at the intercept, the better is the linearity and the lower is the intermodulation distortion (IMD). Third-order products are the most troublesome nonlinear effects for IMD and hence are studied most often. The IP3 value is an imaginary point that is never reached, as the amplifier will saturate before this condition can occur in practice. [6][8]

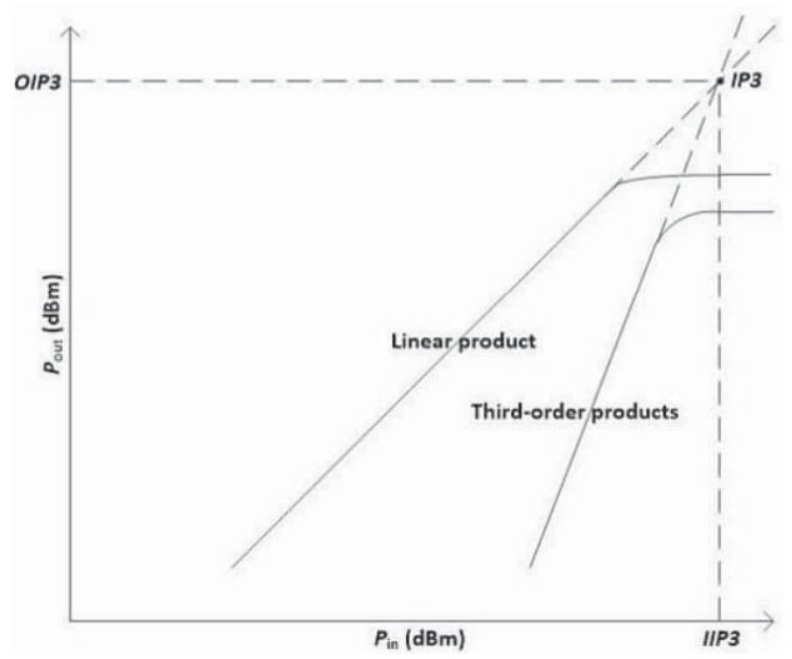

Fig. 3 Third-order intercept diagram for a linear device.

The rule-of-thumb for estimating the OIP3 is

$O I P 3[\mathrm{dBm}] \approx 10 \log _{10}\left(\frac{V_{\mathrm{CEO}} I_{\mathrm{CO}}}{1 \mathrm{~mW}}\right)$ where $V_{C E O}$ and $I_{C O}$ are the quiescent collectoremitter voltage and collector current of a BJT, respectively, normally selected in the middle of the load line within IV-characteristic [9]. The specified values of $V_{C E O}$ and $I_{C O}$ in this project are $4 \mathrm{~V}$ and $10 \mathrm{~mA}$ respectively. The use of this equation results $16 \mathrm{dBm}$ as the approximated value for OIP3.

The Table I lists all the specifications mentioned in this section.

TABLE I

LNA SPECIFICATIONS

\begin{tabular}{|c|c|}
\hline Parameter & Value \\
\hline Gain $(\mathrm{dB})$ & $15(\mathrm{~min})$. \\
\hline Noise Figure $(\mathrm{dB})$ & $1.5(\mathrm{max})$ \\
\hline Input Return Loss $(\mathrm{dB})$ & $7(\mathrm{~min})$. \\
\hline Output Return Loss $(\mathrm{dB})$ & $10(\mathrm{~min})$. \\
\hline OIP3 $(\mathrm{dBm})$ & 16 \\
\hline
\end{tabular}

\section{Simulations}

Simulation was performed using ADS. Stability issue was sorted out first and other specifications were met after fine tuning of different components.

\section{A. DC Bias Simulations}

Current gain ( $\beta$ ) of BJT420 model [7] in ADS was determined by using BJT-curve tracer utility in ADS. It was calculated to be approximately 73 .

Collector-feedback bias was used in the amplifier design as shown in Fig. 4. The values of collector resistance $\left(R_{C}\right)$ and base resistance $\left(R_{B}\right)$ were calculated using the following equations; provided that the collector current was $10 \mathrm{~mA}$ and collector-emitter voltage was $4 \mathrm{~V}$.

$$
I_{\mathrm{B}}=\frac{I_{\mathrm{C}}}{\beta}, R_{\mathrm{C}}=\frac{V_{\mathrm{CC}}-V_{\mathrm{CE}}}{I_{\mathrm{C}}}, R_{\mathrm{B}}=\frac{V_{\mathrm{CE}}-V_{\mathrm{BE}}}{I_{\mathrm{B}}}
$$

The calculated values were $R_{C}=100 \Omega$ and $R_{B}=$ $21.8 \mathrm{k} \Omega$.

\section{B. S-Parameters Simulations}

S-parameter file of BFP420 provided by the manufacturer was used for S-parameters simulations [7]. The circuit diagram is shown in Fig. 5.

1) Substrate: Two-sided FR4 board was used as a printable circuit board with the parameters: 
substrate thickness of $0.8 \mathrm{~mm}$, substrate relative permittivity of 4.5 , copper thickness of $17.5 \mu \mathrm{m}$, and loss tangent of 0.01 .

2) DC Block: 0603 SMD capacitors were used as DC blocks. The graph as shown in Fig. 6 was used to determine the value of capacitance that is resonant at $1.5 \mathrm{GHz}$. It is clear that $22 \mathrm{pF}$ must be the optimal value of capacitance.

3) $\boldsymbol{R F}$ Choke: RF choke or DC feed is used to prevent RF leakage to DC source but it offers negligible impedance for DC flow. In this project, it is implemented with one $22 \mathrm{pF}$ capacitor and one quarter-wave transformer at $1.5 \mathrm{GHz}$. The length of the transformer was determined to be approximately $28 \mathrm{~mm}$.

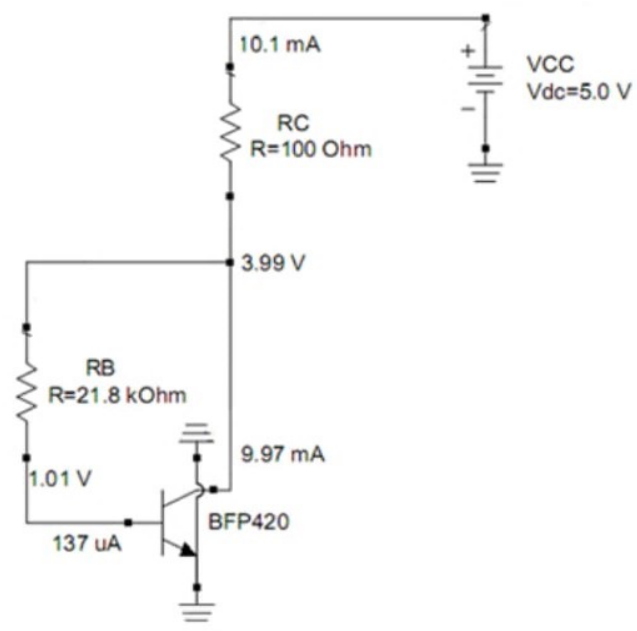

Fig. 4 DC biasing of BFP420.

\section{Stability}

A shunt resistor $\left(R_{\text {stabl }}\right)$ and a series resistor $\left(R_{\text {stab2 }}\right)$ as shown in Fig. 5 under the stabilization network were used to make the amplifier unconditionally stable from $50 \mathrm{MHz}$ to $10 \mathrm{GHz}$.

\section{Input and Output Matching}

It was fortunate that the input section was already noise matched without adding any matching network as shown in the Smith chart of Fig. 7. Output matching network in Fig. 5 with a capacitor and a shunted inductor was added to maximize the gain. The output section was conjugate matched depicted by the Smith chart as shown in Fig. 8.

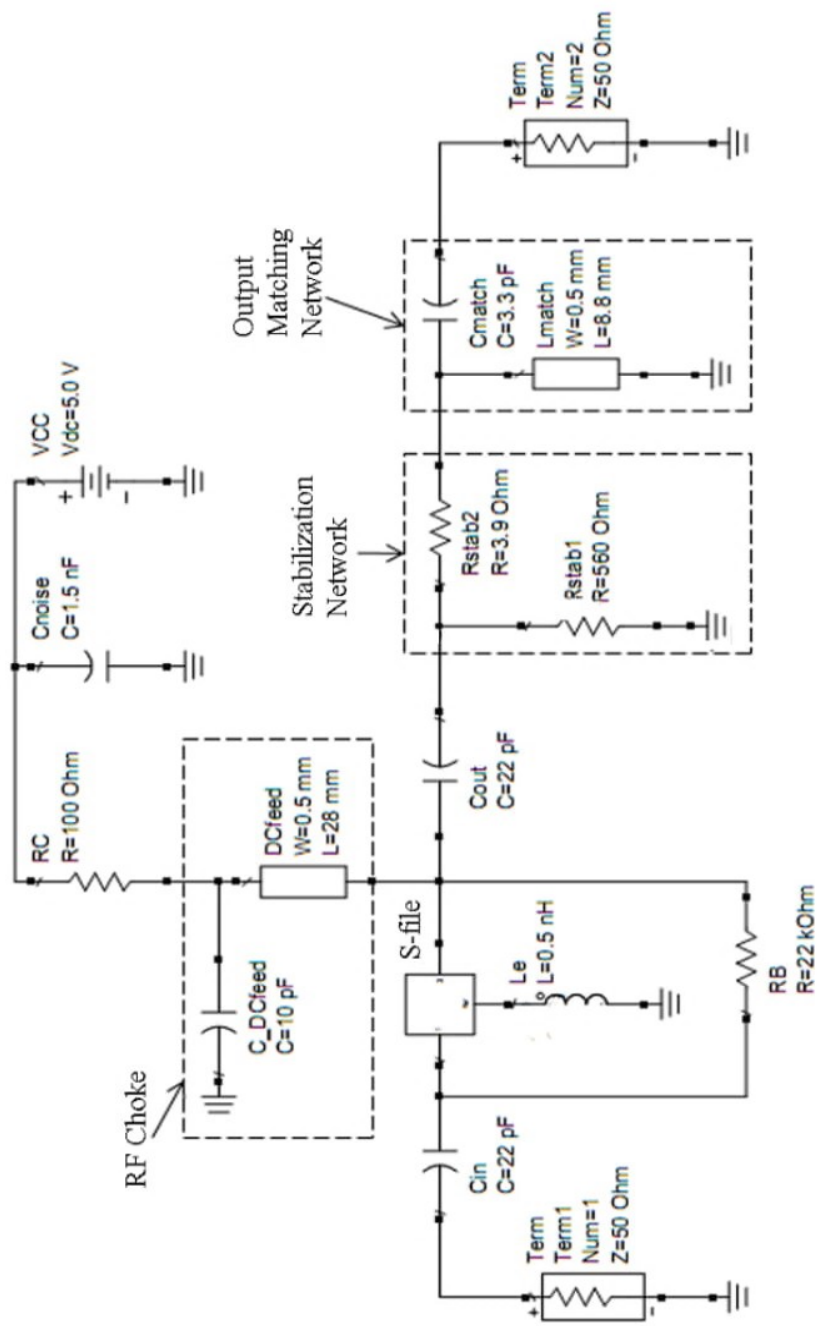

Fig. 5 Circuit diagram of LNA.

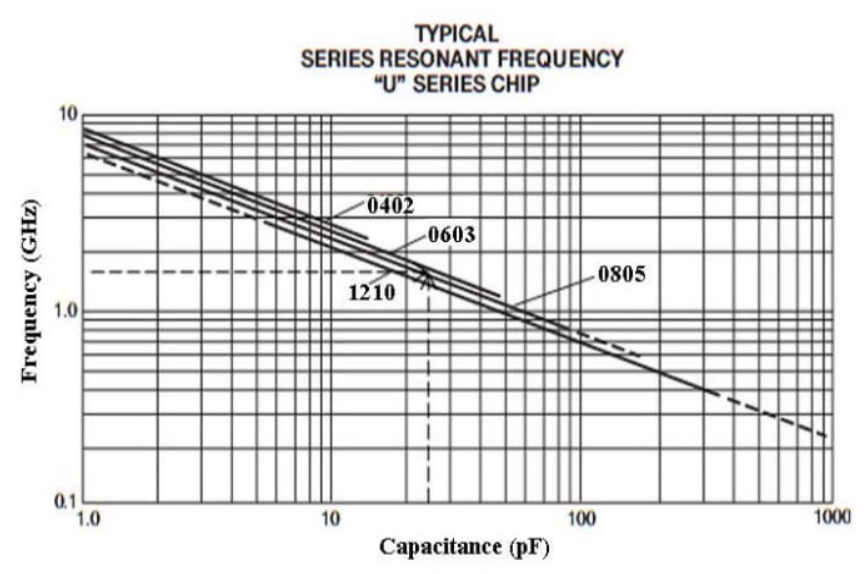

Fig. 6 Capacitor values at resonance. [10] 


\section{Prototype}

After the completion of simulations, a layout was created as shown in Fig. 9. It has size of $27.5 \mathrm{~mm} \times 27.5$ $\mathrm{mm} \approx 7.6 \mathrm{~cm}^{2}$. It was designed such that its size was as small as possible without affecting its performance. The layout was printed on FR4 board and final product was constructed as shown in Fig. 10.

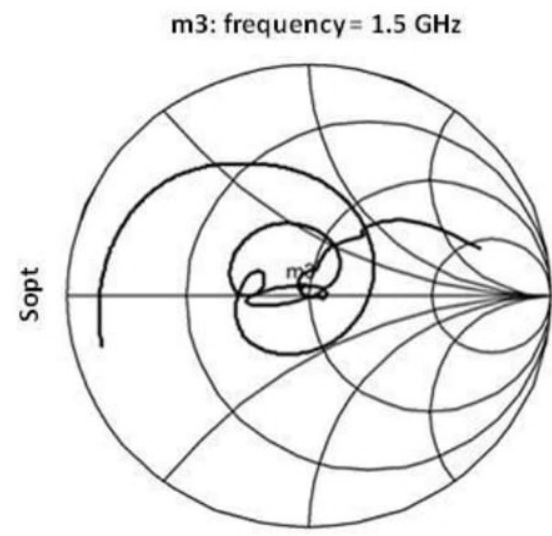

Frequency: $50 \mathrm{MHz}$ to $10 \mathrm{GHz}$

Fig. 7 Plot of $Z_{\text {opt }}$ on $Z_{s}$ line.

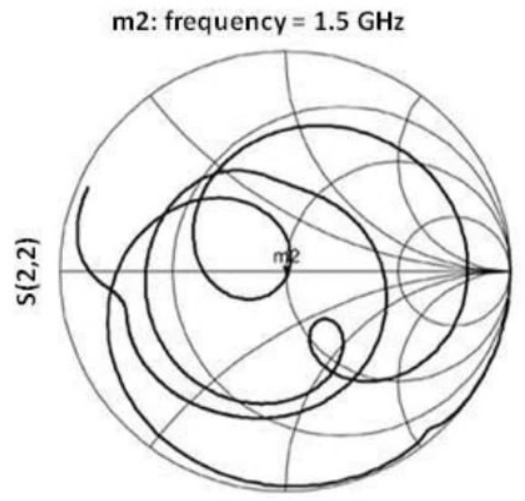

Frequency: $50 \mathrm{MHz}$ to $10 \mathrm{GHz}$

Fig. 8 Plot of $S_{22}$ after matching network.

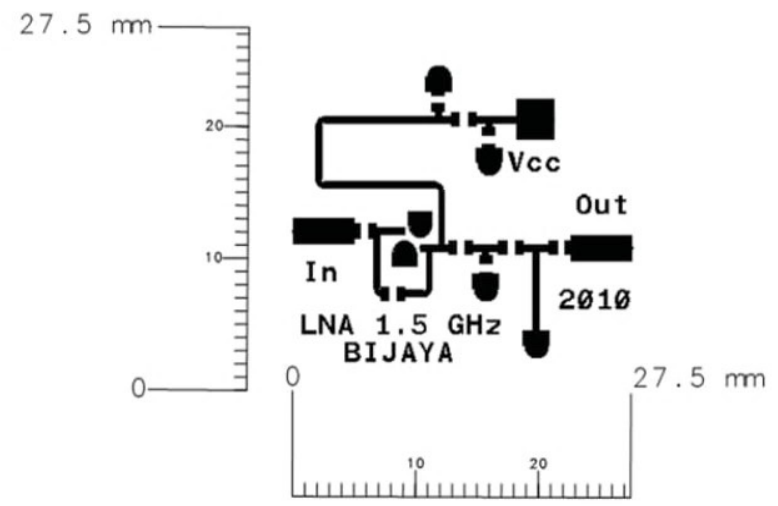

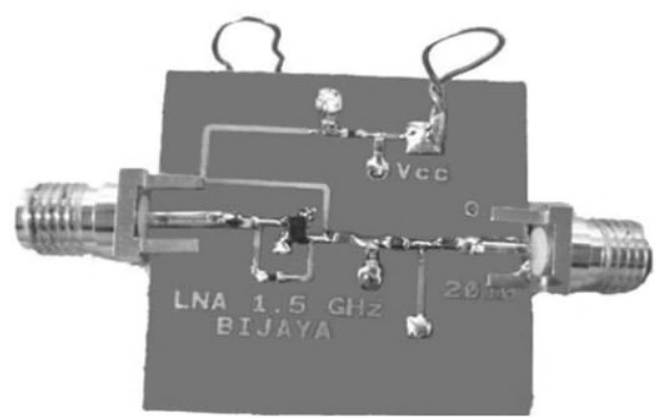

Fig. 10 Prototype of $1.5 \mathrm{GHz}$ LNA.

\section{Results}

This section presents the simulations results and the results from the measurements of the LNA prototype. To get the proper DC bias point of the prototype, the value of base resistor had to be increased to $33 \mathrm{k} \Omega$ from its simulated $22 \mathrm{k} \Omega$. To get the parameters' values close to the simulated results, the output coupling capacitor Cout had to be decreased to $2.2 \mathrm{pF}$ and capacitance of DC feed to $10 \mathrm{pF}$.

The VNA was used to measure the stability factor, gain, input return loss, and output return loss of the LNA. Similarly, the noise figure meter was used to determine the noise figure. And, the OIP3 measurement was carried out with the help of spectrum analyzer. The simulated and measured plots have been included in the same figure so as to ease the comparison analysis.

The plot of stability factor is shown in Fig. 11. This depicts clearly that the LNA is unconditionally stable within the range of $50 \mathrm{MHz}$ to $10 \mathrm{GHz}$.

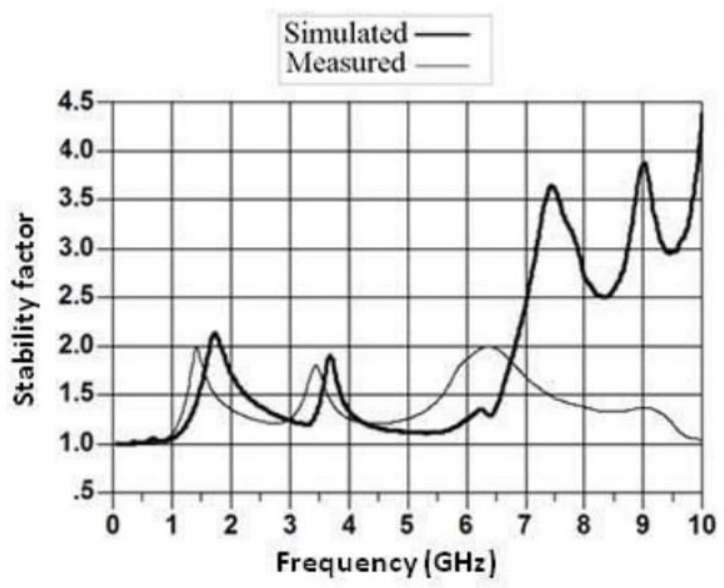

Fig. 11 Stability factor.

Fig. 9 Layout of $1.5 \mathrm{GHz}$ LNA. 
The results of gain, noise figure, input return loss, and output return loss are presented respectively in Fig. $12,13,14$, and 15 respectively. The values of these parameters have been listed in Table II. In the table, ' $\mathrm{S}$ ' represents 'simulated' and 'M' represents 'measured'.

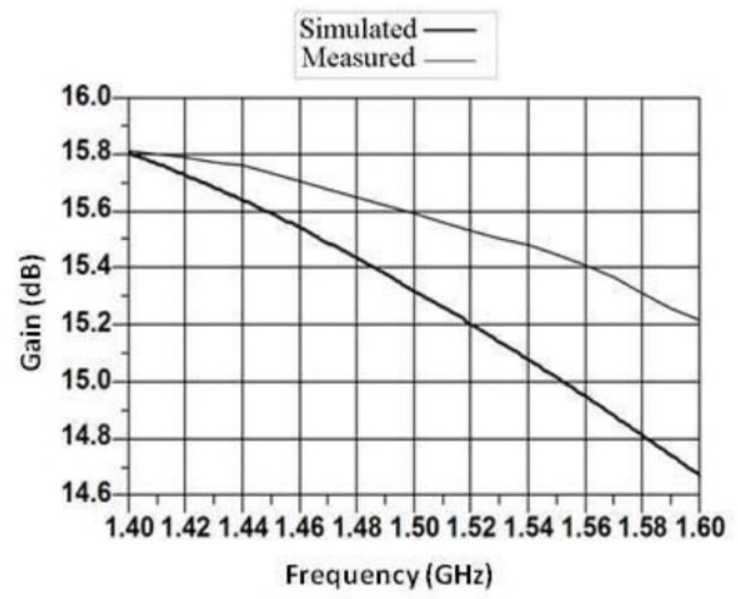

Fig. 12 Gain of LNA.

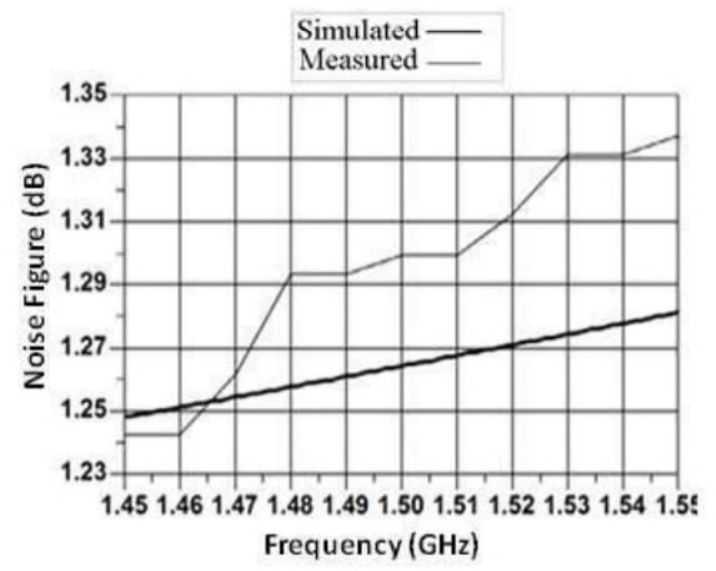

Fig. 13 Noise figure of LNA.

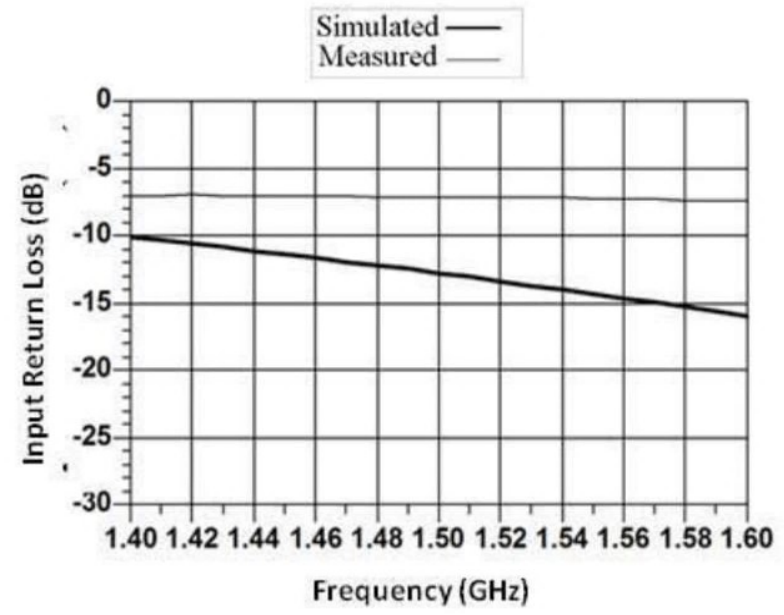

Fig. 14 Input return loss of LNA.

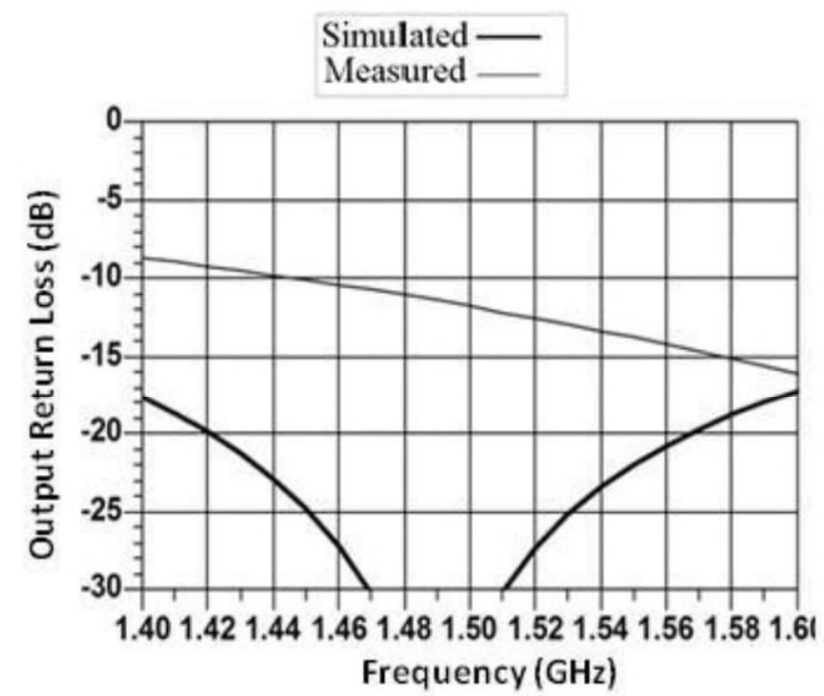

Fig. 15 Output return loss of LNA.

TABLE II

Results

\begin{tabular}{|c|c|c|c|c|c|c|}
\hline \multirow{2}{*}{ Parameter } & \multicolumn{2}{|c|}{$\begin{array}{c}\mathbf{1 4 5 0} \\
\text { MHz }\end{array}$} & \multicolumn{2}{|c|}{$\mathbf{1 5 0 0} \mathbf{M H z}$} & \multicolumn{2}{c|}{$\begin{array}{c}\mathbf{1 5 5 0} \\
\mathbf{M H z}\end{array}$} \\
\cline { 2 - 7 } & S & M & S & M & S & M \\
\hline Gain (dB) & 15.6 & 15.7 & 15.3 & 15.3 & 15 & 15.6 \\
\hline Noise Figure (dB) & 1.25 & 1.24 & 1.26 & 1.3 & 1.2 & 1.34 \\
\hline $\begin{array}{c}\text { Input Return Loss } \\
\text { (dB) }\end{array}$ & 10 & 7 & 12.5 & 7.2 & 14 & 7.3 \\
\hline $\begin{array}{c}\text { Output Return Loss } \\
\text { (dB) }\end{array}$ & 25 & 10 & 34.5 & 12 & 20 & 14 \\
\hline
\end{tabular}

While comparing the results between simulations and measurements, we do not see much difference in gain and noise figure. On the other hand, the difference is prevalent for input return loss and output return loss. This might have resulted due to change in the value of coupling capacitor in the output section. However, both the simulated results and measured results have fulfilled the specified values.

Nonlinear model of transistor was used for the simulations of OIP3. The simulations results are shown in Fig. 16 for three frequencies: $1450 \mathrm{MHz}, 1500 \mathrm{MHz}$, and $1550 \mathrm{MHz}$. 


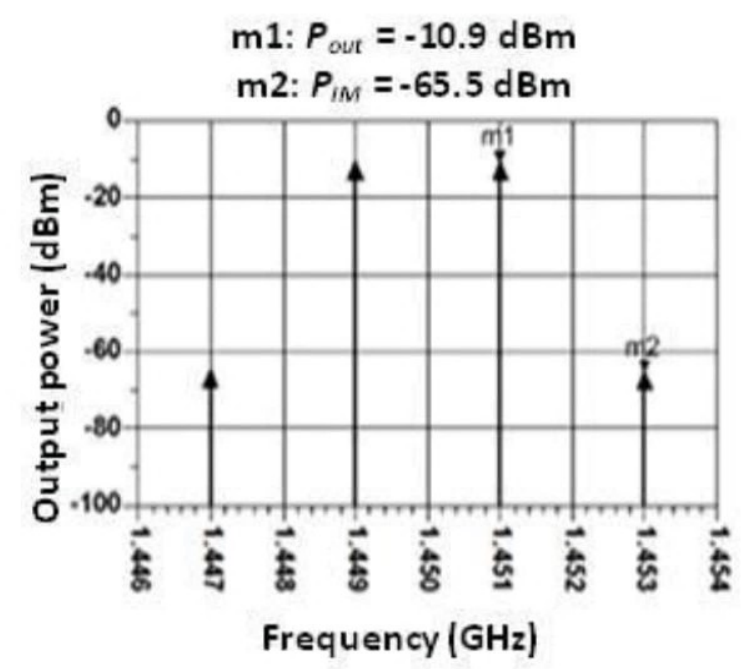

$\mathrm{m} 1: P_{\text {out }}=-11.3 \mathrm{dBm}$ $\mathrm{m} 2: P_{I M}=-66.8 \mathrm{dBm}$

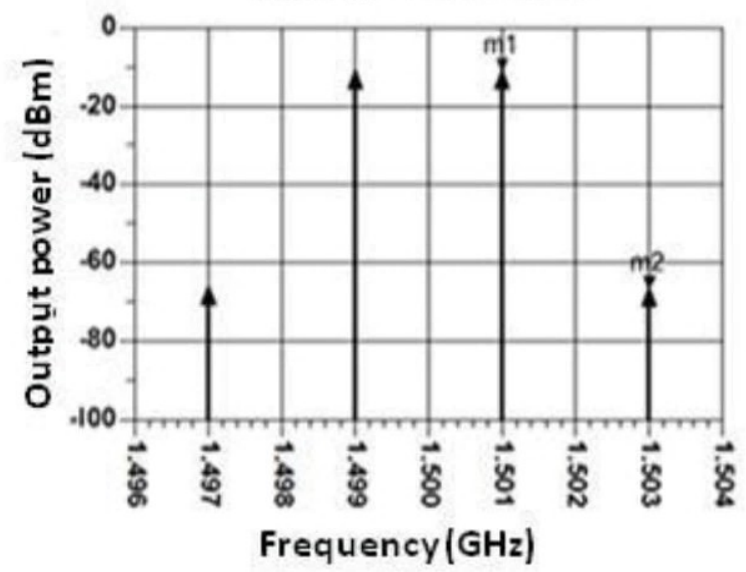

$m 1: P_{\text {out }}=-11.6 \mathrm{dBm}$ $\mathrm{m} 2: P_{I M}=-68 \mathrm{dBm}$

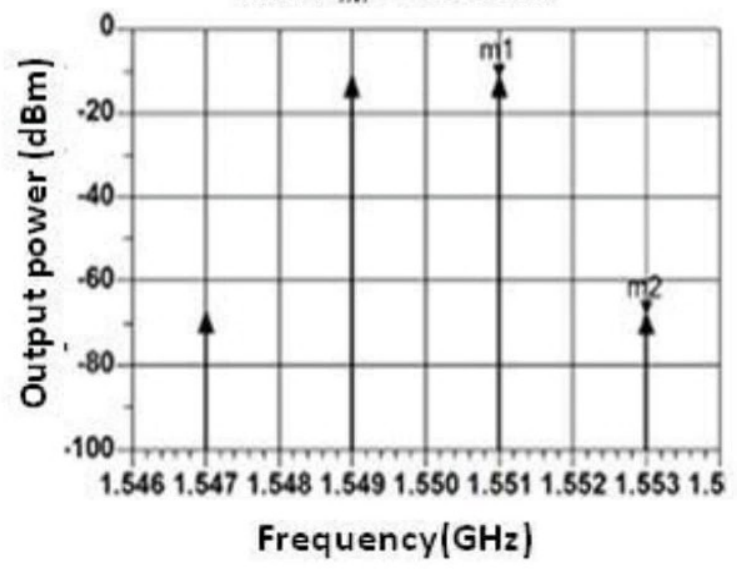

Fig. 16 Simulations results of OIP3.

Here, $P_{\text {out }}$ is the fundamental output power and $P_{I M}$ is the third-order intermodulation power. OIP3 can be calculated using

$$
\text { OIP3 }=P_{\text {out }}+\left(P_{\text {out }}-P_{\text {IM }}\right) / 2
$$

Two signal generators and one spectrum analyzer were used to measure OIP3 at $1450 \mathrm{MHz}, 1500 \mathrm{MHz}$, and $1550 \mathrm{MHz}$. The input power level was set at -20 $\mathrm{dBm}$ and fundamental power $\left(P_{\text {out }}\right)$ and third-order intermodulation power $\left(P_{I M}\right)$ were measured. The necessary data and the calculated OIP3 are tabulated in Table III.

TABLE III

OIP3 Calculations

\begin{tabular}{|c|c|c|c|c|c|c|}
\hline \multirow{2}{*}{ Parameter } & \multicolumn{2}{|c|}{$\mathbf{1 4 5 0} \mathbf{M H z}$} & \multicolumn{2}{|c|}{$\mathbf{1 5 0 0} \mathbf{M H z}$} & \multicolumn{2}{c|}{$\mathbf{1 5 5 0} \mathbf{M H z}$} \\
\cline { 2 - 7 } & $\mathbf{S}$ & $\mathbf{M}$ & $\mathbf{S}$ & $\mathbf{M}$ & $\mathbf{S}$ & $\mathbf{M}$ \\
\hline $\mathrm{P}_{\text {out }}(\mathrm{dBm})$ & -10.9 & -9 & -11.3 & -9.2 & -11.6 & -9.6 \\
\hline $\mathrm{P}_{\text {IM }}(\mathrm{dBm})$ & -65.5 & -55 & -66.8 & -57 & -68 & -58.3 \\
\hline OIP3 $(\mathrm{dBm})$ & 16.4 & 14 & 16.45 & 14.7 & 16.6 & 14.75 \\
\hline
\end{tabular}

The simulated OIP3 has minimum value of 16.4 $\mathrm{dBm}$, whereas, only $14 \mathrm{dBm}$ has been recorded as the minimum measured OIP3. So, the actual value differed from the specified one by $2 \mathrm{dBm}$.

\section{Conclusion}

The specifications were prepared before designing the LNA at $1.5 \mathrm{GHz}$ for the bandwidth of $100 \mathrm{MHz}$. The SMD components were used with BFP420BJT transistor and 0603 resistors and capacitors. The inductors were implemented using the properly calculated transmission lines. The amplifier was simulated, and proper tuning of the components was made to meet the specifications. The LNA was fabricated on the FR4 board. By changing the values of few components, all the specified values of the parameters were obtained. The prototype is unconditionally stable from $50 \mathrm{MHz}$ to $10 \mathrm{GHz}$. The minimum gain of $15.3 \mathrm{~dB}$, the maximum noise figure of $1.34 \mathrm{~dB}$, the minimum input return loss of $7 \mathrm{~dB}$, and the minimum output return loss of $10 \mathrm{~dB}$ were obtained after measuring the LNA prototype. The minimum value of OIP3 was obtained to be $14 \mathrm{dBm}$. Except OIP3, all the parameters met the specifications. Such design can be used to develop LNAs at desired frequencies for mobile communication, satellite communication, and other forms of wireless communication where higher gain is required with the addition of very less noise. The gain can be increased further with multistage configuration. 


\section{References}

[1] S. Pargaien, A. S. Bist, R. Sharma, and A. Patrick, "A Review of $2.4 \mathrm{GHz}$ LNA using Different Topologies in Standard CMOS," International Journal of Engineering Sciences \& Research Technology, March, 2016.

[2] Saman Asgaran, M. Jamal Deen and ChihHung Chen. 'A 4-mW Monolithic CMOS LNA at $5.7 \mathrm{GHz}$ With the Gate Resistance Used for Input Matching [J]'. Microwave and Wireless Components Letters, Volume 16, Issue 4,April 2006, Page(s):188-190

[3] Meng-Ting Hsu, Ting-Yueh Chih and Guo-Rui Li. '1.5V $5 \mathrm{GHz}$ Low Noise AmplifierWith Source Degeneration [C]'. Asia-Pacific Microwave Conference, 2006, Page(s): 405- 408

[4] S. Toofan, A. R. Rahmati, A. Abrishamifar, 'A low power and high-gain fully integrated LNA [J]', Microelectronics Journal, Volume 38, 2007, Page(s): 1150-1155

[5] H. Fouad, K. Sharaf, and E. El-Diwany, 'A Comparison of CMOS and BJT RF-LNAs'. Proceedings of the Nineteenth National Radio Science Conference, March 2002.
[6] D. M. Pozar, Microwave Engineerring, $4^{\text {th }}$ Edition, John Wiley \& Sons, Inc.

[7] Infineon,[Online].Available:https://www.infineon. com/dgdl/Infineon-BFP420-DS-v01_01-en. df?fileId=db3a30431400ef6801142769cd120763. [Accessed 2805 2018].

[8] L. Frenzel. (2018) "What is the Difference Between the Third-Order Intercept and the 1-dB Compression Points?", Oct., 2013. [Online]. Available: http://www.electronicdesign.com

[9] J. Duchon, J. Kangas, and O.P. Lunden, "OIP3 Estimation Based on DC Power Conditions," Microwave Symposium (MMS), 2010 Mediterranean.

[10]AVX, [Online]. Available: http://www farnell. com/datasheets/2239298.pdf? ga=2.196377452.1 134484556.1527483672636073888 .1527483672 . [Accessed 2805 2018]. 